\title{
A Three-Year Follow-up of Glucose Tolerance and Insulin Resistance in Growth Hormone-Deficient (GHD) Children who Underwent Growth Hormone (GH) Replacement Therapy
}

\author{
Megumi Kishi, Yukashi Ohki, Takuya Ohkawa and Hiromi Orimo \\ Department of Pediatrics, Nippon Medical School, Tokyo, Japan
}

\begin{abstract}
We prospectively investigated the effects of growth hormone (GH) replacement therapy on glucose tolerance and insulin resistance. An oral glucose tolerance test (OGTT) was conducted on 36 prepubertal children with GH deficiency (20 boys and 16 girls, 4.9 12.8 yr old) at 0, 0.5, 1, 1.5, 2 and 3 yr after the start of the therapy. As the parameter of glucose tolerance, the sum of 0, 30,60, 120, and 180 min plasma glucose ( $\Sigma \mathrm{PG})(\mathrm{mg} / \mathrm{dl})$, immunoreactive insulin ( $\Sigma \mathrm{IRI})(\mu \mathrm{U} / \mathrm{ml})$, and C-peptide immunoreactivity $(\Sigma \mathrm{CPR})(\mathrm{ng} / \mathrm{ml})$, were used. The homeostasis model assessment ratio (HOMA-R), an index of insulin resistance, and $\beta$-cell function, assessed by the Matthews' formula, was also calculated. $\Sigma$ PG exhibited a significant increase at $1.5 \mathrm{yr}$ after the start of the therapy. $\Sigma$ IRI and $\Sigma$ CPR had increased significantly at $1 \mathrm{yr}$ and thereafter. The blood glucose curve exhibited normal glucose tolerance (NGT) in 33/36, impaired glucose tolerance (IGT) in 3/36, and a diabetic pattern (DM) in 0/36 at the beginning of the therapy. The percentage of subjects exhibiting the IGT increased over time and a DM pattern appeared in some patients. The HOMA-R exhibited a significant increase at $1.5 \mathrm{yr}$. $\beta$-cell function showed a significant increases at 1 and $1.5 \mathrm{yr}$. In summary, increases in insulin resistance and in insulin secretion, and a tendency to an increased blood glucose level were observed after GH therapy. These results showed that careful observation should be conducted about the possibility of developing glucose intolerance during long-term GH therapy.
\end{abstract}

Key words: GH, glucose tolerance, insulin resistance, HOMA

\section{Introduction}

Growth hormone $(\mathrm{GH})$ plays an important role not only in growth but also in glucose, lipid and protein metabolisms (1). Growth hormone initially exerts an insulin-like effect, but it exhibits long-term anti-insulin effects, including a decrease in the utilization of glucose and in insulin

Received: September 1, 2003

Accepted: November 10, 2003

Correspondence: Dr. Megumi Kishi, Department of Pediatrics, Nippon Medical School, 1-1-5, Sendagi, Bunkyoku, Tokyo 113-8603, Japan sensitivity as well as an increase in lipolysis (2). In addition, GH has been shown to directly increase $\beta$ cell proliferation in the pancreas in vitro (3). When GH is administered to healthy subjects, it may increase blood insulin levels and insulin resistance and decrease glucose tolerance, depending on the dose and duration of the treatment (4). Nevertheless, the long-term effects of GH treatment on glucose tolerance and insulin resistance have remained unclear.

Matthews et al. reported a method to evaluate insulin resistance and $\beta$-cell function based on homeostasis model assessment (HOMA) (5). 
These indices can be drawn from fasting plasma glucose and insulin concentrations and are practically useful for repetitive assessment in the out-patient clinic.

Thus, we prospectively studied the effect of GH replacement therapy on glucose tolerance and insulin resistance by using regular oral glucose tolerance tests (OGTT) and a HOMA model in 36 GHD children who underwent GH replacement therapy for $3 \mathrm{yr}$.

\section{Subjects and Methods}

The study subjects were 36 GH-deficient prepubertal children (20 boys and 16 girls) aged between 4.9 and 12.8 yr at the start of GH replacement therapy. GH provocation test revealed that 6 children had complete $\mathrm{GH}$ deficiency. The rest of the children were found to have incomplete GH deficiency. Subjects who showed features of puberty were excluded from the study. The onset of puberty was defined according to the following criteria: $4 \mathrm{ml}$ testis in boys and Tanner stage 2 breast development in girls (6). This study was approved by the Human Study Committee of Nippon Medical School. Written informed consent was obtained from all cases before the study started.

GH replacement therapy was started at a dose of $0.175 \mathrm{mg} / \mathrm{kg} /$ week, and oral glucose tolerance tests (OGTT) were conducted at the start and after $0.5 \mathrm{yr}, 1 \mathrm{yr}, 1.5 \mathrm{yr}, 2 \mathrm{yr}$ and $3 \mathrm{yr}$ of therapy. In the OGTT, glucose tolerance was assessed after a load of $1.75 \mathrm{~g} / \mathrm{kg}$ (the maximum dose: $75 \mathrm{~g}$ ) glucose. Subjects were defined as having diabetes if they met the criteria (fasting plasma glucose $\geq 126 \mathrm{mg}$ / dl or 2-h plasma glucose after O-GTT $\geq 200 \mathrm{mg} / \mathrm{dl}$ ), in accordance with the recommendation of the WHO Expert Committee (7). Subjects who were defined as IGT met the following criteria: fasting plasma glucose $<126 \mathrm{mg} / \mathrm{dl}$ and $140 \mathrm{mg} / \mathrm{dl} \leq 2$-h plasma glucose $<200 \mathrm{mg} / \mathrm{dl}$. $\Sigma \mathrm{PG}$ (plasma glucose) (mg/dl), $\Sigma$ IRI (immunoreactive insulin) $(\mu \mathrm{U} / \mathrm{ml})$ and $\Sigma$ CPR (C-peptide immunoreactivity) (ng/ml)

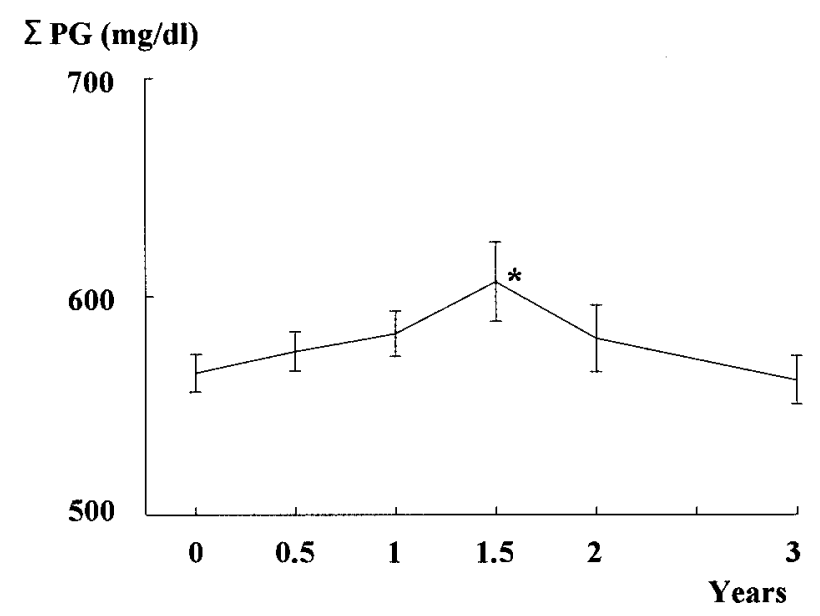

Fig. 1 Changes in $\Sigma \mathrm{PG}$ with GH therapy. ${ }^{*} \mathrm{P}<0.05$.

that were the sum of the values obtained at 0,30 , 60,120 , and $180 \mathrm{~min}$ were used as indices of glucose tolerance. Insulin resistance was assessed with the HOMA model (5). Thus, the homeostasis model assessment ratio (HOMA-R) was calculated with the formula $(\mathrm{FI} \times \mathrm{G}) / 22$, and $\beta$-cell function was calculated with the formula $(20 \times \mathrm{FI}) /(\mathrm{G}-3.5)$. (FI = fasting insulin $(\mu \mathrm{U} / \mathrm{ml}), \mathrm{G}=$ fasting glucose $(\mathrm{mmol} / \mathrm{l}))$

The data are expressed as the mean \pm SEM. Statistical analysis was performed using one-way analysis of variance (ANOVA) and subsequently by Dunnett's test for multiple comparisons unless otherwise indicated. $\mathrm{P}<0.05$ was considered statistically significant.

\section{Results}

\section{Plasma glucose, IRI and C-peptide levels in OGTT}

Changes in $\Sigma$ PG and $\Sigma$ IRI over the period of GH therapy are shown in Fig. 1 and Fig. 2, respectively. $\Sigma$ PG gradually increased and reached the level of significance after $1.5 \mathrm{yr}$ of therapy, but it slightly decreased thereafter. $\Sigma$ IRI showed a significant increase after $1 \mathrm{yr}$, up to $3 \mathrm{yr}$ of therapy. $\Sigma$ CPR also significantly increased after 1 yr (Fig. 3). Full 3-yr data are available in only 56\% 


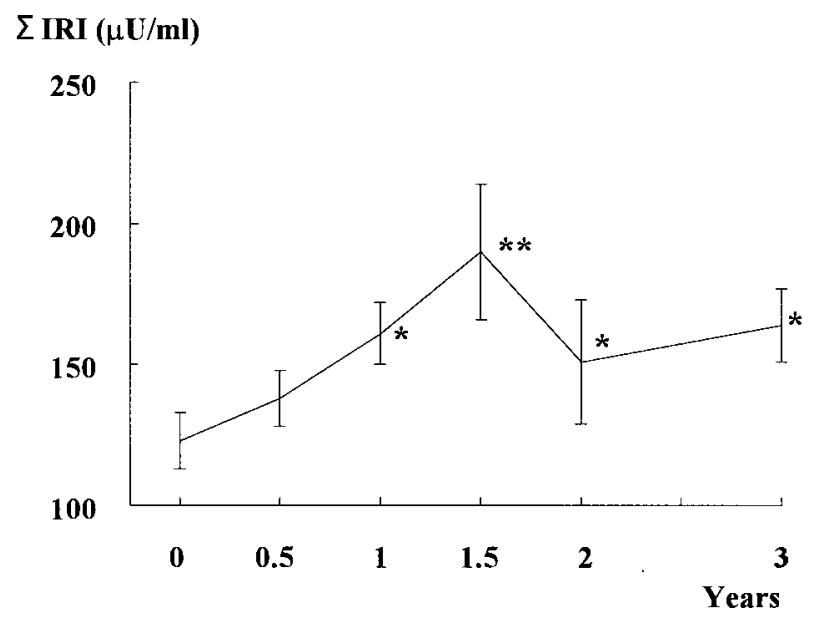

Fig. 2 Changes in $\Sigma$ IRI with GH therapy. ${ }^{*} \mathrm{P}<0.05$, ${ }^{*} \mathrm{P}<0.01$.

of the patients (20/36), but similar results were obtained with the 20 patients who completed the study (data not shown).

\section{Glucose tolerance}

Changes in glucose tolerance over the period of GH therapy are shown in Table 1 . At the start, $92 \%$ of the subjects were considered to have normal glucose tolerance (NGT), and the remaining 8\% were considered to have impaired glucose tolerance (IGT). After 1 yr of the therapy, NGT was observed in less than $70 \%$ of the subjects, showing a significant decrease, and IGT jumped to $31 \%$ (significant increase). The percentage of subjects with IGT steadily increased thereafter. A small number of the subjects were diagnosed to have DM during the GH therapy (0.5 yr and $2 \mathrm{yr}$ ). Two of the 3 subjects initially diagnosed as having

\section{$\sum$ CPR (ng/ml)}

25

20

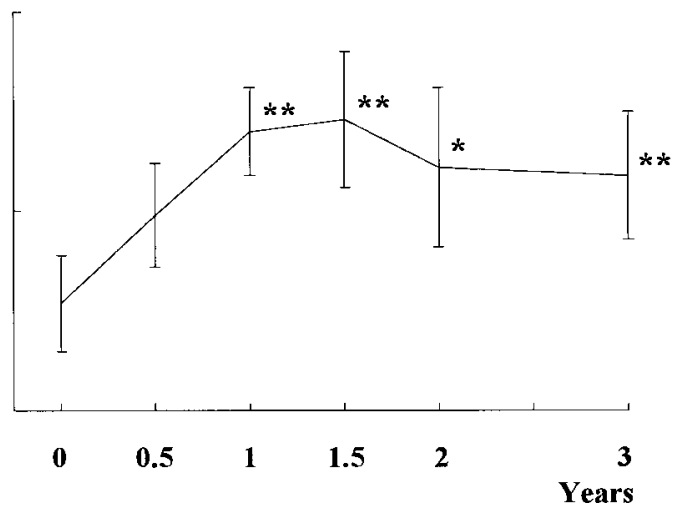

Fig. 3 Changes in $\Sigma C P R$ with $\mathrm{GH}$ therapy. ${ }^{*} \mathrm{P}<0.05$, ${ }^{*} \mathrm{P}<0.01$.

IGT continued to be intolerant of glucose load throughout the study, but one patient showed NGT after the initial study. None of the subjects developed overt DM.

\section{Insulin resistance and $\boldsymbol{\beta}$-cell function}

Figure 4 depicts changes in HOMA-R over the period of GH therapy. HOMA-R values tended to increase up to 1.5 yr of therapy, when the values significantly increased compared with the initial data, but no statistical differences were noted thereafter. $\beta$-cell function also increased after GH replacement therapy. A statistically significant increase in function was observed after $1 \mathrm{yr}$ and 1.5 yr of therapy (Fig. 5). Significant peak values in HOMA-R and $\beta$-cell function at $1.5 \mathrm{yr}$ of therapy were also apparent if we consider only the 20 patients with the full study (data not shown).

Table 1 Changes in glucose tolerance with GH therapy

\begin{tabular}{lcrcccc}
\hline & $0 \mathrm{yr}$ & $0.5 \mathrm{yr}$ & $1 \mathrm{yr}$ & $1.5 \mathrm{yr}$ & $2 \mathrm{yr}$ & $3 \mathrm{yr}$ \\
\hline Normal & $33 / 36$ & $28 / 36$ & $25 / 36^{*}$ & $16 / 24^{*}$ & $14 / 22^{*}$ & $13 / 20^{*}$ \\
IGT & $3 / 36$ & $6 / 36$ & $11 / 36^{*}$ & $8 / 24^{*}$ & $7 / 22^{\star}$ & $7 / 20^{*}$ \\
DM & $0 / 36$ & $2 / 36$ & $0 / 36$ & $0 / 24$ & $1 / 22$ & $0 / 20$ \\
\hline
\end{tabular}

Statistical significance was assessed by $\chi^{2}$-test. ${ }^{*} \mathrm{P}<0.05$ vs 0 yr. 


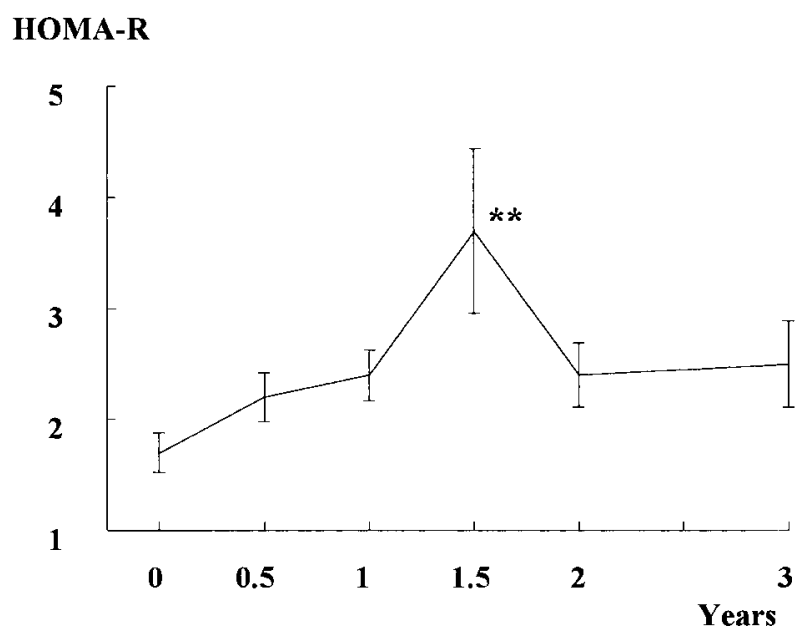

Fig. 4 Changes in HOMA-R with GH therapy. ${ }^{*} \mathrm{P}<0.01$

\section{Discussion}

We prospectively assessed glucose tolerance, insulin secretion, and insulin resistance by regular OGTT in 36 GHD children (20 males and 16 females) who underwent GH replacement therapy, to study the effect of GH replacement therapy on glucose metabolism. Our study demonstrated that $\Sigma \mathrm{PG}$ increased after $1.5 \mathrm{yr}$ of the GH therapy, suggesting an aggravation of glucose tolerance. Tsunoda et al. (8) reported that the mean prepubertal $\Sigma$ PG value in normal non-obese children (7-11 yr of age) is $528.8 \pm 41.0$, but our value after $1.5 \mathrm{yr}$ of the therapy was higher than this, suggesting more hyperglycemia than in the general population at this phase of therapy. This was also the case with the increase in $\Sigma$ IRI and $\Sigma$ CPR after 1 yr or longer-GH therapy since the normal values were $122.0 \pm 38.9$ and $18.9 \pm 4.5$, respectively (8). Therefore, our study indicated that insulin secretion increases with GH therapy, as was also reported in prior studies (9-11).

We then assessed insulin resistance. The glucose clamp method is the standard method of obtaining an index of insulin resistance, but the sampling is difficult and less practicable for outpatient use (12). On the other hand, a method

\section{$\beta$-Cell function}

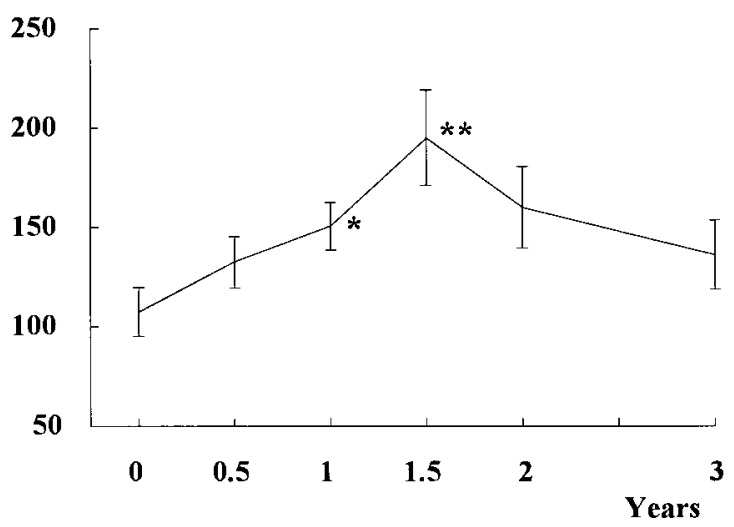

Fig. 5 Changes in $\beta$-cell function with GH therapy. ${ }^{*} \mathrm{P}<0.05,{ }^{*} \mathrm{P}<0.01$.

described by Matthews et al. (5) is considered practicable and highly useful. This method involves the homeostasis model assessment ratio (HOMA-R) and $\beta$ cell function calculated from fasting blood glucose and insulin levels, based on the feedback loop theory between fasting insulin and glucose levels. Matthews et al. assumed that $\beta$ cell function is $100 \%$, and that insulin resistance is 1.0 in healthy subjects aged 35 or younger with normal body weight. In this study, we assessed insulin resistance over the period of GH therapy by using this HOMA model. HOMA-R significantly increased after $1.5 \mathrm{yr}$ of therapy compared to the values at the start. Kawahara et al. (13) estimated HOMA-R in 66 obese subjects aged between 19 and 66 , and reported that it was $2.54 \pm 1.27$ in the subjects with NGT, $2.44 \pm 0.84$ in the subjects with IGT, and $4.90 \pm 2.49$ in the subjects with DM. Matsumoto et al. (15) studied the normal values of HOMA-R in 530 non-obese subjects and 226 obese subjects and reported that HOMA-R was $1.44 \pm 0.08$ in the non-obese subjects with IGT, $1.97 \pm 0.08$ in the subjects with DM, $2.63 \pm 0.17$ in the obese subjects with IGT and $3.13 \pm 0.16$ in the obese subjects with DM. Our insulin resistance value after 1.5 yr $(3.7 \pm 0.7)$ was comparable to that observed in the obese subjects with DM. Kanauchi 
et al. (14) performed 75-g OGTT in 551 Japanese subjects, and classified them into NGT (238 subjects), IGT (211) and Type 2 DM (102). In the study by Kanauchi et al., HOMA-R was reported to be $1.62 \pm 0.96$ in the subjects with NGT, $1.96 \pm 1.23$ in the subjects with IGT and $2.23 \pm 1.37$ in the subjects with Type $2 \mathrm{DM}$, and $\beta$-cell function was reported to be $93.7 \pm 58.5$ in the subjects with NGT, $93.4 \pm 76.8$ in the subjects with IGT, and $58.9 \pm 41.5$ in the subjects with Type 2 DM. Again, our results suggest that insulin resistance after $1.5 \mathrm{yr}$ of GH therapy is comparable to that observed in the subjects with IGT or DM, and insulin secretion also increased after $1 \mathrm{yr}, 1.5 \mathrm{yr}$ and $2 \mathrm{yr}$ of GH therapy compared with normal secretion.

The effects of $\mathrm{GH}$ therapy on insulin resistance have been reported by other investigators. Heptulla et al. studied insulin sensitivity in 8 short children aged between 8 and 16 before and after $0.3 \mathrm{mg} / \mathrm{kg} /$ week $\mathrm{GH}$ therapy for 6 mo, by using a hyperglycemic clamp method (9). They reported that insulin sensitivity rapidly decreased after GH therapy, and that hyperinsulinemia compensated for decreased insulin sensitivity. Gravholt et al. (10) conducted a 2-mo double blind placebo controlled study on 0.1 $\mathrm{IU} / \mathrm{kg} /$ day GH therapy in 12 female subjects with Turner's syndrome aged between 9.5 and $14.8 \mathrm{yr}$ and 16 age-matched female controls and assessed insulin resistance using a HOMA model after OGTT. They reported that HOMA indices and insulin secretion significantly increased in the GH therapy group. Cutfield et al. assessed insulin sensitivity by using Bergman's minimal model before, during and after rhGH (recombinant human growth hormone) therapy in 12 short nonGHD children born small for gestational age (11). Insulin sensitivity significantly decreased by $44 \% \pm$ $10 \%$ during the $21 \pm 6$-mo rhGH therapy, while insulin secretion was $123 \% \pm 59 \%$, showing a significant compensatory increase. They also reported that decreased insulin sensitivity did not recover even at 3 mo after completion of the therapy.
With respect to the mechanism of insulin resistance induced by GH, Takano et al. studied the effect of GH on insulin cascade signaling using 3T3$\mathrm{L} 1$ adipocytes (16). They reported that when the blood GH level was maintained at a high concentration for a long time, uncoupling between PI 3-kinase and Akt in the downstream insulin signal transduction pathways occurred and induced insulin resistance. Thus, previous reports suggest that GH replacement therapy results in decreased insulin sensitivity and increased insulin secretion in both the clinical and the experimental setting, which is consistent with our results.

In summary, we conducted GH replacement therapy in 36 GHD children who had never undergone this therapy and assessed glucose tolerance and insulin resistance after regular OGTT. Aggravation of glucose tolerance after 1.5 yr of the therapy, an increase in insulin secretion from after $1 \mathrm{yr}$, and aggravation of insulin resistance after 1.5 yr were observed. As changes in glucose metabolism in accordance with WHO criteria, a significant decrease in the number of subjects with NGT and a significant increase in the number of subjects with IGT were observed after 3 yr of GH therapy. Thus, long-term GH therapy could induce glucose intolerance and insulin resistance, although overt DM may not develop. We suggest that careful follow-up should be conducted about the risk of developing glucose intolerance in patients with long-term GH treatment.

\section{References}

1. Davidson MB. Effect of growth hormone on carbohydrate and lipid metabolism. Endocr Rev 1987;8:115-31.

2. MacGorman LR, Rizza RA, Gerich JE. Physiological concentrations of growth hormone exert insulin-like and insulin antagonistic effects on both hepatic and extrahepatic tissues in man. J Clin Endocrinol Metab 1981;53:556-9.

3. Billestrup N, Nielsen JH. The stimulatory effect of growth hormone, prolactin, and placental lactogen 
on $\beta$-cell proliferation is not mediated by insulinlike growth factor-I. Endocrinology 1991;129:8838.

4. Rizza RA, Mandarino LJ, Gerich JE. Effects of growth hormone on insulin action in man. Mechanisms of insulin resistance, impaired suppression of glucose production, and impaired stimulation of glucose utilization. Diabetes 1982;31:663-9.

5. Matthews DR, Hosker JP, Rudenski AS, Naylor BA, Treacher DF, Turner RC. Homeostasis model assessment: insulin resistance and $\beta$-cell function from fasting plasma glucose and insulin concentrations in man. Diabetologia 1985;28:4129.

6. Tanaka T, Takano K, Igarashi Y, Hanew K, Nishi Y, Tachibana $\mathrm{K}$, et al. Growth hormone (GH) treatment and puberty in GH-treated GH deficient children. Clin Pediatr Endocrinol 1999;8(Suppl 12):37-44.

7. Alberti KGMM, Zimmet PZ for the WHO consultation. Definition, diagnosis and classification of diabetes mellitus and its complications. Part 1: Diagnosis and classification of diabetes mellitus provisional report of a WHO consultation. Diabet Med 1998;15:539-53.

8. Tsunoda M, Ohki Y, Mineda T, Teshirogi T. Studies on insulin secretion and clearance in obese and diabetic children (7 11 years old) and adolescents (12 16 years old). Investigation by oral glucose tolerance tests (O-GTT). J Nippon Med Sch 1992;59:9-20 (in Japanese).

9. Heptulla RA, Boulware SD, Caprio S, Silver D, Sherwin RS, Tamborlane WV. Decreased insulin sensitivity and compensatory hyperinsulinemia after hormone treatment in children with short stature. J Clin Endocrinol Metab 1997;82:3234-8.

10. Gravholt CH, Naeraa RW, Brixen K, Kastrup KW,
Mosekilde L, Jørgensen JOL, et al. Short-term growth hormone treatment in girls with Turner syndrome decreases fat mass and insulin sensitivity: A randomized, double-blind, placebocontrolled, crossover study. Pediatrics 2002;110:889-96.

11. Cutfield WS, Jackson WE, Jefferies C, Robinson EM, Breier BH, Richards GE, et al. Reduced insulin sensitivity during growth hormone therapy for short children born small for gestational age. J Pediatr 2003;142:113-6.

12. Maehata E, Yano M, Shiba T, Yamakado M, Inoue M, Suzuki S. Insulin resistance index (HOMA-R method). Nippon Rinsho 2002;60(Suppl 8):34150 (in Japanese).

13. Kawahara R, Yoshino M, Tasaka Y, Nagase N, Watanabe C, Togashi M, et al. Relationship between plasma leptin levels and insulin resistance in obese subjects with glucose intolerance. J Japan Diab Soc 1998;41:443-7 (in Japanese).

14. Matsumoto K, Yamaguchi Y, Miyake S, Akazawa S, Yano M, Tominaga Y, et al. Glucose tolerance, insulin secretion, and insulin sensitivity in nonobese and obese Japanese subjects. Diabetes Care 1997;20:1562-8.

15. Kanauchi M, Nakajima M, Saito Y, Kanauchi K. Pancreatic beta-cell function and insulin sensitivity in Japanese subjects with impaired glucose tolerance and newly diagnosed type 2 diabetes mellitus. Metabolism 2003;52:476-81.

16. Takano A, Haruta T, Iwata M, Usui I, Uno T, Kawahara J, et al. Growth hormone induces cellular insulin resistance by uncoupling phosphatidylinositol 3-kinase and its downstream signals in 3T3-L1 adipocytes. Diabetes 2001;50:1891-900. 